\title{
The Role of Toll-Like Receptors in Osteoclastogenesis
}

\author{
Mijung Yim \\ College of Pharmacy, Sookmyung Women's University, Seoul, Korea
}

\author{
Corresponding author \\ Mijung Yim \\ College of Pharmacy, Sookmyung Women's \\ University, 100 Cheongpa-ro 47-gil, \\ Yongsan-gu, Seoul 04310, Korea \\ Tel: +82-2-710-9572 \\ Fax: +82-2-710-9871 \\ E-mail: myim@sookmyung.ac.kr
}

Received: September 28, 2020

Revised: October 14, 2020

Accepted: October 19, 2020
Bone homeostasis is maintained by a balance in the levels of osteoclast and osteoblast activity. Osteoclasts are bone-resorbing cells and have been shown to act as key players in various osteolytic diseases. Osteoclasts differentiate from monocyte/macrophage lineage cells in the presence of receptor activator of nuclear factor-KB ligand and macrophage colony-stimulating factor. Osteoblasts support osteoclastogenesis by producing several osteoclast differentiation factors. Toll-like receptors (TLRs) are members of the pattern recognition receptor family that are involved in recognizing pathogen-associated molecular patterns and damage-associated molecular patterns in response to pathogen infection. TLRs regulate osteoclastogenesis and bone resorption through either the myeloid differentiation primary response 88 or the Toll/interleukin-1 receptor domaincontaining adapter-inducing interferon- $\beta$ signaling pathways. Since osteoclasts play a central role in the progression of osteolytic diseases, extensive research focusing on TLR downstream signaling in these cells should be conducted to advance the development of effective TLR modulators. In this review, we summarize the currently available information on the role of TLRs in osteoclast differentiation and osteolytic diseases.

Key Words: Bone diseases · Osteoclasts · Osteolysis

\section{INTRODUCTION}

Bone is continuously remodeled throughout life-old bone is resorbed by osteoclasts, while new bone is formed by osteoblasts.[1,2] Osteoclasts are the key players involved in the maintenance of bone homeostasis; however, an excess of osteoclast activity leads to pathological bone loss as seen in diseases, such as osteoporosis, arthritis, periodontitis, and several metastatic cancers.[2] Therefore, understanding osteoclast biology is important from a clinical perspective.

Osteoclasts are derived from monocyte/macrophage lineage cells. Two indispensable factors are required for osteoclast differentiation: receptor activator of nuclear factor (NF)-KB ligand (RANKL) and macrophage colony-stimulating factor (M-CSF).[3,4] M-CSF is essential for the proliferation and survival of osteoclast precursors and guides the early step of osteoclastogenesis.[5] On the other hand, RANKL directly differentiates osteoclast precursors into mature osteoclasts by binding to its receptor RANK.[6] RANKL/RANK binding activates the NF of activated T cells (NFATC1), the master transcription factor for osteoclast differentiation, which induces the expression of various osteoclast-specific genes, such as tartrate-resis-
Mineral Research

This is an Open Access article distributed under the terms of the Creative Commons Attribution Non-Commercial License (https://creativecommons.org/licenses/by-nc/4.0/) which permits unrestricted non-commercial use, distribution, and reproduction in any medium, provided the origina work is properly cited.

\section{KSBMR}


tant acid phosphatase, cathepsin K, and dendritic cell-specific transmembrane protein.[7-10] Additionally, the synergistic activation of RANKL/RANK signaling by immunoreceptor tyrosine-based activation motif-containing proteins, DNAX-activating protein of $12 \mathrm{kDa}$, and Fcy receptor has been reported.[11,12]

Although RANKL is the primary factor responsible for osteoclast differentiation, many studies have validated the involvement of other pathways in osteoclastogenesis. Among them, the presence of Toll-like receptors (TLRs) on osteoclasts and osteoclast precursors has attracted attention due to their regulatory roles in osteolytic diseases. In this review, we will briefly summarize the functions of TLRs, and their roles in osteoclast differentiation.

\section{TLRS AND THEIR LIGANDS}

TLRs are members of the pattern recognition receptor family. All TLRs have common structures consisting of an amino (N)-terminal extracellular domain with leucine-rich repeats, a single transmembrane spanning region, and a carboxyl (C)-terminal cytoplasmic Toll/interleukin (IL)-1 receptor (TIR) signaling domain.[13,14] To date, 10 human TLRs (TLR1-10) and 12 mouse TLRs (TLR1-9 and 11-13) have been identified.[15] TLRs are generally divided into 2 subgroups, depending on their cellular locations: TLR1, TLR2, TLR4, TLR5, and TLR6 are mainly present on the surface of plasma membranes, while TLR3, TLR7, TLR8, and TLR9 reside on the intracellular membranes of endosomes, lysosomes, and endolysosomes.[16]

The ligands recognized by TLRs are known as pathogenassociated molecular patterns, and include different types of molecules. For example, the ligands for TLR1, TLR2, TLR6, and TLR10 are bacterial lipoproteins and peptidoglycans. The ligands for TLR4 or TLR5 are bacterial lipopolysaccharides or flagellin. TLR3 is a sensor for viral double-stranded RNA, while TLR7 and TLR8 bind viral single-stranded RNA, TLR9 binds to CPG DNA, and TLR11 and TLR12 recognize profilin from Toxoplasma gondii.[17]

Danger-associated molecular patterns are endogenous nucleic acids and proteins released by stressed cells, and they can act as ligands for TLRs_-TLR3 detects cellular RNA; TLR7, TLR8, and TLR9 recognize cellular RNA or DNA; while TLR4 senses secreted cellular proteins, such as high-mobility group box 1 , heat-shock proteins, and S100 family of proteins.[18-20]

\section{TLR SIGNALING}

The first step in TLR activation is the formation of heteroor homo-dimers. TLR2 heterodimerizes with TLR1 and TLR6, [21] and possibly TLR10.[22] In contrast, TLR4 typically forms homodimers.[23,24] After these conformational changes, TLRs recruit cytoplasmic TIR-domain containing adaptor proteins, such as myeloid differentiation factor 88 (MyD88), TIR domain-containing adaptor protein (TIRAP or MyD88 like [Mal]), TIR-domain-containing adapter-inducing interferon (IFN)- $\beta$ (TRIF), IFN- $\beta$-related adaptor molecule (TRAM), and sterile- $\alpha$ and armadillo motif-containing protein.[25] Among them, TLRs mainly use the MyD88 and TRIF pathways. All TLRs, except TLR3, use the MyD88-dependent pathway, whereas TLR3 and TLR4 use the TRIF-dependent pathway.[26] The recruitment of these adaptor proteins leads to the activation of downstream transcription factors via serial association with various ubiquitin ligases and kinases (Fig. 1).

\section{The MyD88-dependent pathway}

All TLRs, except TLR3, use the MyD88-dependent pathway to activate downstream signaling. TLR2 and TLR4 require an additional adaptor protein, TIRAP (or Mal) for this pathway.[27] MyD88 has 3 structural domains: a death domain, an intermediate domain, and a C-terminal TIR domain.[28] MyD88 associates with TLRs through its TIR domain.[29]

Upon association with TLRs, MyD88 recruits IL-1 receptor-associated kinase (IRAK) 4 and, subsequently, IRAK1 and IRAK2. Activated IRAK1 binds to tumor necrosis factor (TNF) receptor-associated factor (TRAF) 6, an E3 ubiquitin ligase. This IRAK1/TRAF6 complex recruits the protein kinase transforming growth factor- $\beta$-activated kinase 1 (TAK1), which phosphorylates IkB kinase $\beta$, which, in turn, phosphorylates $\mathrm{I} \mathrm{KBa}$. The phosphorylation of IKBa releases NF$\mathrm{KB}$ (p65/p50), allowing its nuclear translocation, binding to response elements, and transcription of target genes.[30,31] On the other hand, TAK1 also activates the mitogen-activated protein kinase (MAPK) signaling pathway.[32] The MyD88-dependent activation of NF-KB and MAPKs induces the expression of various inflammatory cytokines such as IL-1 $\beta$ and TNF-a.[30-32] 


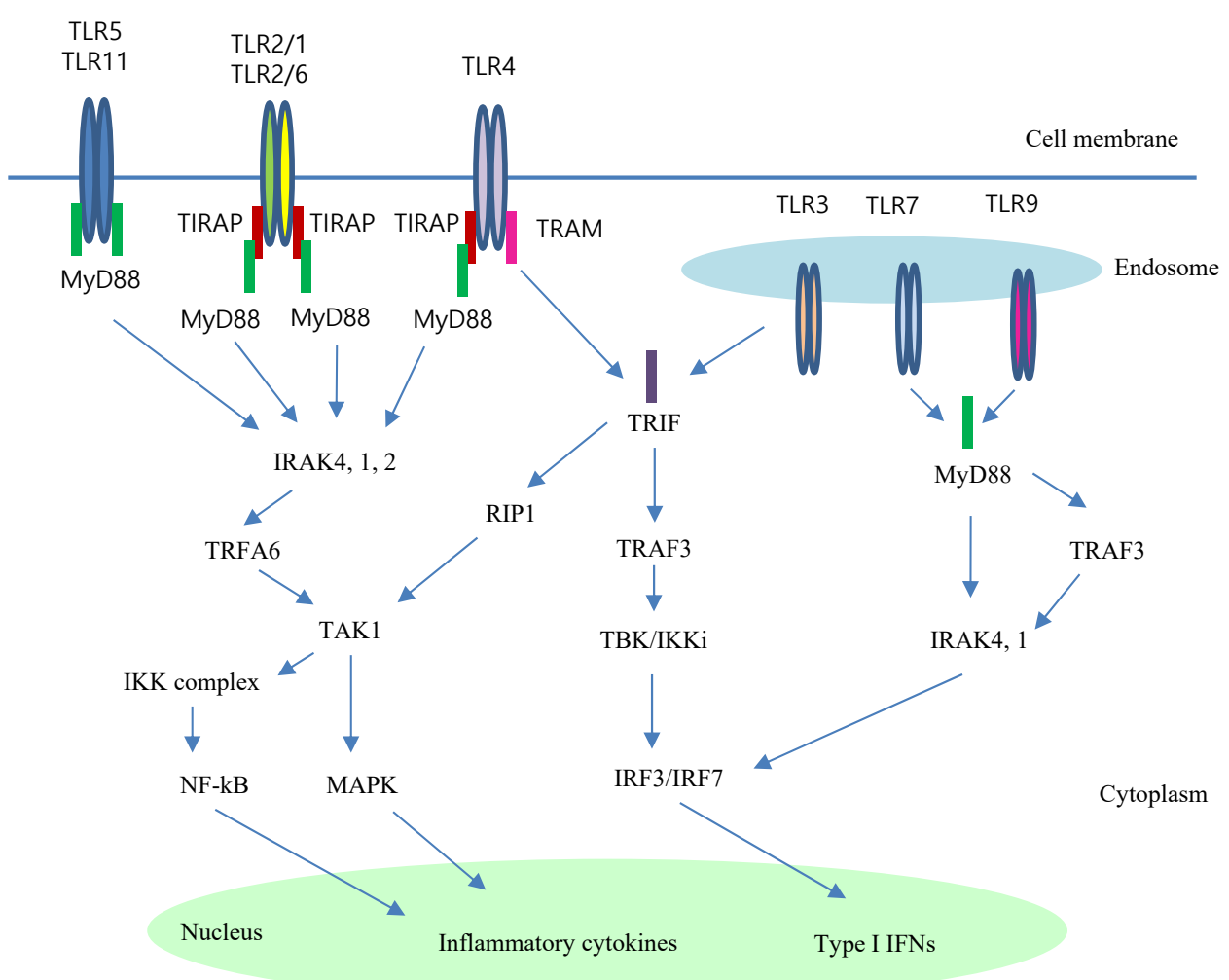

Fig. 1. Toll-like receptor (TLR) signaling pathways. TLRs are located on the surface of cell membranes or endosomal compartments. The activation of different TLRs recruit specific sets of adaptors. All TLRs, except TLR3, use the myeloid differentiation factor 88 (MyD88)-dependent pathway, whereas TLR3 and TLR4 use the TLR domain-containing adapter-inducing interferon- $\beta$ (TRIF)-dependent pathway. Recruitment of the various signaling adaptors activate downstream signaling pathways to provoke the induction of pro-inflammatory cytokines or the production of type I interferons (IFNs). TIRAP, toll-like receptor domain-containing adaptor protein; IRAK, interleukin-1 receptor-associated kinase; TRF, T-cell replacing factor; TAK, transforming growth factor- $\beta$-activated kinase; IKK, IKB kinase; NF-KB, nuclear factor-KB; MAPK, mitogen-activated protein kinase; RIP, receptor-interacting protein; TRAF, tumor necrosis factor receptor-associated factor; IRF, interferon regulatory factor.

\section{The TRIF-dependent pathway}

The endosomal TLRs (TLR3 and TLR4) mediate the TRIFdependent pathway to activate NF-KB (TLR4) or to produce IFN- $\beta$ (TLR3 and TLR4).[33] TLR3 directly, and TLR4 indirectly, recruit TRIF via the association of a TRAM, an adaptor protein. TRIF, in turn, recruits receptor-interacting protein (RIP) 1, TRAF3, and TRAF6, and the polyubiquitination of these proteins activates TAK1.[34] TAK1 induces delayed activation of NF-KB in a manner similar to the MyD88-dependent pathway, leading to the activation of IFN regulatory factor 3 (IRF3).[25,35] Activated IRF3s dimerize, translocate to the nucleus, and bind to IFN-sensitive responsive element to induce transcription of the IFN- $\beta$ gene and the IFN-stimulated genes. $[36,37]$ In addition, TRIF appears to regulate TLR-induced cell death via RIP3 and caspase-8. [38] This mechanism explains how immune cells cause cell death in response to intracellular bacterial infection. $[39,40]$

\section{THE ROLE OF TLRS IN OSTEOCLAST DIFFERENTIATION}

\section{Direct effect of TLRs on osteoclastogenesis}

Osteoclasts express TLRs, and the expression pattern of TLRs varies depending on the stage of osteoclastogenesis. Osteoclast precursors express TLR1-TLR9; however, during their differentiation into mature osteoclasts, only TLR2 and TLR4 are predominantly expressed,[41] suggesting that these 2 TLRs play a major role during osteoclastogenesis.

The role of TLRs in osteoclast differentiation has been investigated using both in vitro and in vivo model systems. [42-47] Both positive and negative effects of TLRs on osteoclast differentiation have been reported in vitro. These 
contradictory effects of TLRs appear to be dependent on the stage of cell differentiation

In mouse bone marrow-derived macrophage and human peripheral blood monocyte cultures, the simultaneous addition of TLR ligands with RANKL inhibits osteoclast formation. $[41,48]$ Therefore, it is possible that TLR signaling sequesters the downstream molecules from the RANKL signaling pathway, resulting in inhibition of osteoclastogenesis.

Despite their negative effects during the early stages of osteoclastogenesis, TLRs play a positive role at the later stages of osteoclast differentiation, once osteoclast precursors are committed to the osteoclast lineage.[49,50] For example, if osteoclast precursors are pre-treated with RANKL for at least $24 \mathrm{hr}$, the activation of TLRs promoted osteoclastogenesis in the presence of RANKL. Furthermore, once osteoclast precursors are primed with RANKL, simulation of TLRs is sufficient to induce osteoclast formation even in the absence of RANKL. Since RANKL priming alone does not induce osteoclast formation, it is thought to permit differentiation toward osteoclasts, and this commitment in osteoclast lineage is required for the positive role of TLRs in osteoclastogenesis.

NFATC1 is a master transcription factor of osteoclastogenesis, and appears to serve as a gatekeeper for the dual role of TLRs. $[9,10]$ The activation of TLRs in uncommitted osteoclast precursors abolished RANKL-induced NFATc1 expression; however, it enhanced NFATc1 expression in RANKL-primed cells.[41,50,51]

The inhibitory function of TLRs in uncommitted cells is partly mediated by IFN- $\beta$ production.[52] TLR3 and TLR4 induce IFN- $\beta$ through a TRIF-dependent signaling mechanism.[26,53] The TRIF-dependent signaling pathway promotes the formation of a homodimer of IRF3,[54] resulting in activation of the IFN- $\beta$ promoter. Binding of IFN- $\beta$ to its receptor (IFNAR) triggers the activation of Janus kinase and signal transducer and activator of transcription signaling, resulting in the inhibition of c-Fos expression, further abolishing NFATc1 activation.[55] The IFN- $\beta / c$-Fos axis is an important negative feedback mechanism in osteoclast differentiation. Moreover, the deletion of IFN- $\beta$ or IFNAR increases the number of osteoclasts in vivo, further demonstrating the importance of this pathway.[55-57]

On the other hand, the activation of TLRs in committed cells triggers a number of downstream signaling molecules.
$[50,51,58,59]$ These pathways allow NF-kB to translocate into the nucleus, stimulate the transcription of NFATc1, and release several inflammatory cytokines, such as TNF-a, IL-1, and IL-6. This pro-osteoclastogenic effect of TLRs appears to be mediated via the MyD88-dependent pathway,[51] since the deletion of MyD88 reduced the number of osteoclasts in vivo. In addition, TLRs are believed to have pro-survival effects on mature osteoclasts via the Akt, NF-kB, and extracellular signal-regulated kinase pathways.[50]

Although TLRs have biphasic effects on osteoclast differentiation in vitro, they demonstrate a positive effect on osteoclastogenesis and bone destruction in vivo. Systemic injection of TLR4 ligand significantly increases the number of osteoclasts, resulting in femoral bone loss in vivo. $[60,61]$ In periodontitis models, the injection of TLR2 or TLR4 ligand into the gingiva of the lower mandible also causes alveolar bone loss.[62,63] In rheumatoid arthritis (RA) preclinical models, the positive effects of TLR2, 4, 5, and 7 have been demonstrated. Intraarticular injection of TLR2 or TLR4 ligand induces joint inflammation and chronic destructive arthritis.[64,65] Local injection of TLR5 ligand potentiates joint inflammation and arthritic bone destruction in collagen-induced arthritis (CIA) models.[66] Furthermore, the deletion of TLR7 decreases joint inflammation and the arthritis-induced bone loss in $\mathrm{CIA}$ and $\mathrm{K} / \mathrm{BxN}$ serum transfer arthritis models.[67,68]

In contrast, the functions of TLR3 and TLR9 vary in vivo, depending on the experimental conditions. It has been reported that TLR3 is involved in pristane-induced arthritis. [69] Furthermore, activation of TLR3 promotes joint inflammation, while deletion of TLR3 reduces $\mathrm{K} / \mathrm{BxN}$ serum transfer arthritis.[68,70] However, systemic injection of TLR3 Iigand attenuates collagen antibody-induced arthritis via anti-inflammatory type I IFNs.[71] The dual function of TLR9 has also been demonstrated in vivo. The activation of TLR9 induces arthritis via the upregulation of pro-inflammatory cytokines [72]; however, it reduces disease manifestation in $\mathrm{K} / \mathrm{BxN}$ serum transfer arthritic models.[73]

\section{Indirect effect of TLRs on osteoclastogenesis}

Osteoblasts are derived from mesenchymal stem cells and can modulate osteoclast formation via direct contact with osteoclast precursors.[74,75] RANKL is essential for osteoclast differentiation, and its effect is abrogated by osteoprotegerin (OPG), a soluble decoy receptor for RANK. 
Among many factors expressed by osteoblasts, the ratio of RANKL to OPG is thought to be critical for the regulation of osteoclast formation.[75]

TLRs are expressed on the surface of osteoblasts and indirectly modulate osteoclast differentiation.[76] The activation of TLR2, 4, 5, and 9 in osteoblasts enhances osteoclast formation and bone loss by increasing the RANKL/ OPG ratio.[77-81] Myd88-dependent activation of MAPK and NF-KB is generally considered to be responsible for the stimulatory effect of TLRs on RANKL expression.[78] TLRs in osteoblasts also stimulate the production of inflammatory cytokines IL- $1 \beta$, TNF- $\alpha$, and IL- 6 , as well as prostaglandins, which further contribute to osteoclast differentiation by osteoblasts.[49,82] Recently, it has been reported that bacterial infection induces periodontal bone loss via increased RANKL production by the osteocytes.[83] Therefore, the TLR regulation of osteoclastogenesis via osteocytes needs further investigation.

\section{CONCLUDING REMARKS}

Osteoclasts are key players in osteolytic diseases, such as osteoporosis, RA, and periodontitis. Upon infection, the activation of TLRs induces osteoclast differentiation, leading to bone and joint destruction. Many efforts have been made to understand TLR-mediated osteoclastogenesis using in vitro and in vivo osteolytic disease models. Various studies suggest that targeting the mechanism by which TLRs mediate osteoclast differentiation could be a promising therapeutic strategy for the development of novel antiosteolytic drugs. Given that there are limited options for patients suffering from inflammatory osteolytic diseases, targeting TLR-mediated signaling pathways would provide additional opportunities for effective treatment of these diseases. Currently, several modulators of TLRs are under clinical evaluation for various diseases.[84] The elucidation of the regulatory mechanism of TLRs specific for osteoclastmediated osteolysis would be helpful to develop new drugs for precision medicine.

\section{DECLARATIONS}

\section{Acknowledgments}

This study was supported by research funding from the Korean Society for Bone and Mineral Research.

\section{Ethics approval and consent to participate Not applicable.}

\section{Conflict of interest}

No potential conflict of interest relevant to this article was reported.

ORCID

Mijung Yim https://orcid.org/0000-0001-9320-8078

\section{REFERENCES}

1. Zaidi M. Skeletal remodeling in health and disease. Nat Med 2007;13:791-801. http://dx.doi.org/10.1038/nm1593.

2. Rodan GA, Martin TJ. Therapeutic approaches to bone diseases. Science 2000;289:1508-14. http://dx.doi.org/10.1126/ science.289.5484.1508.

3. Suda T, Takahashi N, Udagawa N, et al. Modulation of osteoclast differentiation and function by the new members of the tumor necrosis factor receptor and ligand families. Endocr Rev 1999;20:345-57. http://dx.doi.org/10.1210/ edrv.20.3.0367.

4. Boyle WJ, Simonet WS, Lacey DL. Osteoclast differentiation and activation. Nature 2003;423:337-42. http://dx.doi.org/ 10.1038/nature01658.

5. Kodama $H$, Nose M, Niida S, et al. Essential role of macrophage colony-stimulating factor in the osteoclast differentiation supported by stromal cells. J Exp Med 1991;173: 1291-4. http://dx.doi.org/10.1084/jem.173.5.1291.

6. Anderson DM, Maraskovsky E, Billingsley WL, et al. A homologue of the TNF receptor and its ligand enhance T-cell growth and dendritic-cell function. Nature 1997;390:1759. http://dx.doi.org/10.1038/36593.

7. Matsuo K, Galson DL, Zhao C, et al. Nuclear factor of activated T-cells (NFAT) rescues osteoclastogenesis in precursors lacking c-Fos. J Biol Chem 2004;279:26475-80. http:// dx.doi.org/10.1074/jbc.M313973200.

8. Wagner EF, Eferl R. Fos/AP-1 proteins in bone and the immune system. Immunol Rev 2005;208:126-40. http://dx. doi.org/10.1111/j.0105-2896.2005.00332.x.

9. Takayanagi H, Kim S, Koga T, et al. Induction and activation of the transcription factor NFATc1 (NFAT2) integrate RANKL signaling in terminal differentiation of osteoclasts. Dev Cell 2002;3:889-901. http://dx.doi.org/10.1016/s15345807(02)00369-6. 
10. Kim JH, Kim N. Regulation of NFATc1 in osteoclast differentiation. J Bone Metab 2014;21:233-41. http://dx.doi.org/ 10.11005/jbm.2014.21.4.233.

11. Koga $T$, Inui $M$, Inoue $K$, et al. Costimulatory signals mediated by the ITAM motif cooperate with RANKL for bone homeostasis. Nature 2004;428:758-63. http://dx.doi.org/ 10.1038 /nature02444.

12. Mócsai A, Humphrey MB, Van Ziffle JA, et al. The immunomodulatory adapter proteins DAP12 and Fc receptor gamma-chain (FcRgamma) regulate development of functional osteoclasts through the Syk tyrosine kinase. Proc Natl Acad Sci U S A 2004;101:6158-63. http://dx.doi.org/10.1073/ pnas. 0401602101

13. Medzhitov R. Toll-like receptors and innate immunity. Nat Rev Immunol 2001;1:135-45. http://dx.doi.org/10.1038/ 35100529.

14. Botos I, Segal DM, Davies DR. The structural biology of Tolllike receptors. Structure 2011;19:447-59. http://dx.doi.org/ 10.1016/j.str.2011.02.004.

15. Rehli M. Of mice and men: species variations of Toll-like receptor expression. Trends Immunol 2002;23:375-8. http: //dx.doi.org/10.1016/s1471-4906(02)02259-7.

16. McGettrick AF, O'Neill LA. Localisation and trafficking of Toll-like receptors: an important mode of regulation. Curr Opin Immunol 2010;22:20-7. http://dx.doi.org/10.1016/ j.coi.2009.12.002.

17. Mancini RJ, Stutts L, Ryu KA, et al. Directing the immune system with chemical compounds. ACS Chem Biol 2014;9: 1075-85. http://dx.doi.org/10.1021/cb500079s.

18. Piccinini AM, Midwood KS. DAMPening inflammation by modulating TLR signalling. Mediators Inflamm 2010;2010. http://dx.doi.org/10.1155/2010/672395.

19. Foell D, Wittkowski H, Vogl T, et al. S100 proteins expressed in phagocytes: a novel group of damage-associated molecular pattern molecules. J Leukoc Biol 2007;81:28-37. http://dx.doi.org/10.1189/jlb.0306170.

20. Tsung $A$, Klune JR, Zhang $X$, et al. HMGB1 release induced by liver ischemia involves Toll-like receptor 4 dependent reactive oxygen species production and calcium-mediated signaling. J Exp Med 2007;204:2913-23. http://dx.doi. org/10.1084/jem.20070247.

21. Zhang H, Tay PN, Cao W, et al. Integrin-nucleated Toll-like receptor (TLR) dimerization reveals subcellular targeting of TLRs and distinct mechanisms of TLR4 activation and signaling. FEBS Lett 2002;532:171-6. http://dx.doi.org/10. 1016/s0014-5793(02)03669-4.

22. Oosting M, Cheng SC, Bolscher JM, et al. Human TLR10 is an anti-inflammatory pattern-recognition receptor. Proc Natl Acad Sci U S A 2014;111:E4478-84. http://dx.doi.org/ 10.1073/pnas.1410293111.

23. Ozinsky A, Underhill DM, Fontenot JD, et al. The repertoire for pattern recognition of pathogens by the innate immune system is defined by cooperation between toll-like receptors. Proc Natl Acad Sci U S A 2000;97:13766-71. http:// dx.doi.org/10.1073/pnas.250476497.

24. Ozinsky A, Smith KD, Hume D, et al. Co-operative induction of pro-inflammatory signaling by Toll-like receptors. J Endotoxin Res 2000;6:393-6.

25. O'Neill LA, Bowie AG. The family of five: TIR-domain-containing adaptors in Toll-like receptor signalling. Nat Rev Immunol 2007;7:353-64. http://dx.doi.org/10.1038/nri2079.

26. Yamamoto $M$, Sato $S$, Hemmi $H$, et al. Role of adaptor TRIF in the MyD88-independent toll-like receptor signaling pathway. Science 2003;301:640-3. http://dx.doi.org/10.1126/ science. 1087262 .

27. Yamamoto M, Sato S, Hemmi H, et al. Essential role for TIRAP in activation of the signalling cascade shared by TLR2 and TLR4. Nature 2002;420:324-9. http://dx.doi.org/10.1038/ nature01182.

28. O'Neill LA, Dunne A, Edjeback M, et al. Mal and MyD88: adapter proteins involved in signal transduction by Tolllike receptors. J Endotoxin Res 2003;9:55-9. http://dx.doi. org/10.1179/096805103125001351.

29. Yamamoto M, Takeda K, Akira S. TIR domain-containing adaptors define the specificity of TLR signaling. Mol Immunol 2004;40:861-8. http://dx.doi.org/10.1016/j.molimm. 2003.10.006.

30. O'Neill LA. Signal transduction pathways activated by the IL-1 receptor/toll-like receptor superfamily. Curr Top Microbiol Immunol 2002;270:47-61.

31. Warner N, Núñez G. MyD88: a critical adaptor protein in innate immunity signal transduction. J Immunol 2013; 190:3-4. http://dx.doi.org/10.4049/jimmunol.1203103.

32. Brown J, Wang $H$, Hajishengallis $G N$, et al. TLR-signaling networks: an integration of adaptor molecules, kinases, and cross-talk. J Dent Res 2011;90:417-27. http://dx.doi. org/10.1177/0022034510381264

33. Yamamoto $M$, Sato $S$, Mori $K$, et al. Cutting edge: a novel Toll/IL-1 receptor domain-containing adapter that preferentially activates the IFN-beta promoter in the Toll-like re- 
ceptor signaling. J Immunol 2002;169:6668-72. http://dx. doi.org/10.4049/jimmunol.169.12.6668.

34. Jiang $Z$, Johnson $\mathrm{HJ}$, Nie $\mathrm{H}$, et al. Pellino 1 is required for interleukin-1 (IL-1)-mediated signaling through its interaction with the IL-1 receptor-associated kinase 4 (IRAK4)IRAK-tumor necrosis factor receptor-associated factor 6 (TRAF6) complex. J Biol Chem 2003;278:10952-6. http:// dx.doi.org/10.1074/jbc.M212112200.

35. Jiang Z, Mak TW, Sen G, et al. Toll-like receptor 3-mediated activation of NF-kappaB and IRF3 diverges at Toll-IL-1 receptor domain-containing adapter inducing IFN-beta. Proc Natl Acad Sci U S A 2004;101:3533-8. http://dx.doi. org/10.1073/pnas.0308496101.

36. Hiscott J. Triggering the innate antiviral response through IRF-3 activation. J Biol Chem 2007;282:15325-9. http:// dx.doi.org/10.1074/jbc.R700002200.

37. Yang P, An H, Liu X, et al. The cytosolic nucleic acid sensor LRRFIP1 mediates the production of type I interferon via a beta-catenin-dependent pathway. Nat Immunol 2010;11: 487-94. http://dx.doi.org/10.1038/ni.1876.

38. Kaiser WJ, Sridharan H, Huang C, et al. Toll-like receptor 3-mediated necrosis via TRIF, RIP3, and MLKL. J Biol Chem 2013;288:31268-79. http://dx.doi.org/10.1074/jbc.M113. 462341.

39. Ruckdeschel K, Pfaffinger G, Haase R, et al. Signaling of apoptosis through TLRs critically involves toll/IL-1 receptor domain-containing adapter inducing IFN-beta, but not MyD88, in bacteria-infected murine macrophages. J Immunol 2004;173:3320-8. http://dx.doi.org/10.4049/jimmunol.173.5.3320.

40. De Trez C, Pajak B, Brait M, et al. TLR4 and Toll-IL-1 receptor domain-containing adapter-inducing IFN-beta, but not MyD88, regulate Escherichia coli-induced dendritic cell maturation and apoptosis in vivo. J Immunol 2005;175: 839-46. http://dx.doi.org/10.4049/jimmunol.175.2.839.

41. Takami M, Kim N, Rho J, et al. Stimulation by toll-like receptors inhibits osteoclast differentiation. J Immunol 2002; 169:1516-23. http://dx.doi.org/10.4049/jimmunol.169.3. 1516.

42. Bar-Shavit Z. Taking a toll on the bones: regulation of bone metabolism by innate immune regulators. Autoimmunity 2008; 41:195-203. http://dx.doi.org/10.1080/08916930701694469.

43. O'Neill LA. Primer: Toll-like receptor signaling pathways-what do rheumatologists need to know? Nat Clin Pract Rheumatol 2008;4:319-27. http://dx.doi.org/10.1038/ ncprheum0802.

44. Goh FG, Midwood KS. Intrinsic danger: activation of Tolllike receptors in rheumatoid arthritis. Rheumatology (Oxford) 2012;51:7-23. http://dx.doi.org/10.1093/rheumatology/ker257.

45. Jiménez-Dalmaroni MJ, Gerswhin ME, Adamopoulos IE. The critical role of toll-like receptors--From microbial recognition to autoimmunity: A comprehensive review. Autoimmun Rev 2016;15:1-8. http://dx.doi.org/10.1016/ j.autrev.2015.08.009.

46. Elshabrawy HA, Essani AE, Szekanecz Z, et al. TLRs, future potential therapeutic targets for RA. Autoimmun Rev 2017; 16:103-13. http://dx.doi.org/10.1016/j.autrev.2016.12.003.

47. Souza PPC, Lerner UH. Finding a toll on the route: The fate of osteoclast progenitors after toll-like receptor activation. Front Immunol 2019;10:1663. http://dx.doi.org/10.3389/ fimmu.2019.01663.

48. Zhang P, Liu J, Xu Q, et al. TLR2-dependent modulation of osteoclastogenesis by Porphyromonas gingivalis through differential induction of NFATc1 and NF-kappaB. J Biol Chem 2011;286:24159-69. http://dx.doi.org/10.1074/jbc.M110. 198085.

49. Zou W, Bar-Shavit Z. Dual modulation of osteoclast differentiation by lipopolysaccharide. J Bone Miner Res 2002;17: 1211-8. http://dx.doi.org/10.1359/jbmr.2002.17.7.1211.

50. Liu J, Wang S, Zhang $P$, et al. Molecular mechanism of the bifunctional role of lipopolysaccharide in osteoclastogenesis. J Biol Chem 2009;284:12512-23. http://dx.doi.org/10. 1074/jbc.M809789200.

51. Chen Z, Su L, Xu Q, et al. IL-1R/TLR2 through MyD88 divergently modulates osteoclastogenesis through regulation of nuclear factor of activated T cells c1 (NFATc1) and B lymphocyte-induced maturation protein-1 (Blimp1). J Biol Chem 2015;290:30163-74. http://dx.doi.org/10.1074/jbc. M115.663518.

52. Lee $\mathrm{Y}$, Huang $\mathrm{H}$, Kim HJ, et al. The phosphatidylinositol 3kinase-mediated production of interferon-beta is critical for the lipopolysaccharide inhibition of osteoclastogenesis. Life Sci 2008;83:369-76. http://dx.doi.org/10.1016/ j.lfs.2008.07.002.

53. O'Neill LA. How Toll-like receptors signal: what we know and what we don't know. Curr Opin Immunol 2006;18:39. http://dx.doi.org/10.1016/j.coi.2005.11.012.

54. Honda K, Yanai H, Takaoka A, et al. Regulation of the type I IFN induction: a current view. Int Immunol 2005;17:1367- 
78. http://dx.doi.org/10.1093/intimm/dxh318.

55. Takayanagi H, Kim S, Matsuo K, et al. RANKL maintains bone homeostasis through c-Fos-dependent induction of interferon-beta. Nature 2002;416:744-9. http://dx.doi.org/ 10.1038/416744a.

56. $\mathrm{Ha} \mathrm{H}$, Lee JH, Kim HN, et al. Stimulation by TLR5 modulates osteoclast differentiation through STAT1/IFN-beta. J Immunol 2008;180:1382-9. http://dx.doi.org/10.4049/jimmunol.180.3.1382.

57. Abraham AK, Ramanathan M, Weinstock-Guttman B, et al. Mechanisms of interferon-beta effects on bone homeostasis. Biochem Pharmacol 2009;77:1757-62. http://dx.doi. org/10.1016/j.bcp.2009.01.007.

58. Suda K, Woo JT, Takami M, et al. Lipopolysaccharide supports survival and fusion of preosteoclasts independent of TNF-alpha, IL-1, and RANKL. J Cell Physiol 2002;190:1018. http://dx.doi.org/10.1002/jcp.10041.

59. Ohgi K, Kajiya H, Goto TK, et al. Toll-like receptor 2 activation primes and upregulates osteoclastogenesis via lox-1. Lipids Health Dis 2018;17:132. http://dx.doi.org/10.1186/ s12944-018-0787-4.

60. Sakuma Y, Tanaka K, Suda M, et al. Impaired bone resorption by lipopolysaccharide in vivo in mice deficient in the prostaglandin E receptor EP4 subtype. Infect Immun 2000; 68:6819-25. http://dx.doi.org/10.1128/iai.68.12.6819-6825. 2000.

61. Miyaura C, Inada M, Matsumoto $C$, et al. An essential role of cytosolic phospholipase A2alpha in prostaglandin E2mediated bone resorption associated with inflammation. J Exp Med 2003;197:1303-10. http://dx.doi.org/10.1084/ jem.20030015.

62. Matsumoto C, Oda T, Yokoyama S, et al. Toll-like receptor 2 heterodimers, TLR2/6 and TLR2/1 induce prostaglandin E production by osteoblasts, osteoclast formation and inflammatory periodontitis. Biochem Biophys Res Commun 2012;428:110-5. http://dx.doi.org/10.1016/j.bbrc.2012.10.016.

63. Kimura K, Kitaura H, Fujii T, et al. An anti-c-Fms antibody inhibits osteoclastogenesis in a mouse periodontitis model. Oral Dis 2014;20:319-24. http://dx.doi.org/10.1111/odi. 12117.

64. Abdollahi-Roodsaz S, Joosten LA, Helsen MM, et al. Shift from toll-like receptor 2 (TLR-2) toward TLR-4 dependency in the erosive stage of chronic streptococcal cell wall arthritis coincident with TLR-4-mediated interleukin-17 production. Arthritis Rheum 2008;58:3753-64. http://dx.doi. org/10.1002/art.24127.

65. Joosten LA, Abdollahi-Roodsaz S, Heuvelmans-Jacobs $M$, et al. T cell dependence of chronic destructive murine arthritis induced by repeated local activation of Toll-like receptor-driven pathways: crucial role of both interleukin1beta and interleukin-17. Arthritis Rheum 2008;58:98-108. http://dx.doi.org/10.1002/art.23152.

66. Kim SJ, Chen Z, Chamberlain ND, et al. Ligation of TLR5 promotes myeloid cell infiltration and differentiation into mature osteoclasts in rheumatoid arthritis and experimental arthritis. J Immunol 2014;193:3902-13. http://dx.doi. org/10.4049/jimmunol.1302998.

67. Alzabin S, Kong P, Medghalchi M, et al. Investigation of the role of endosomal Toll-like receptors in murine collagen-induced arthritis reveals a potential role for TLR7 in disease maintenance. Arthritis Res Ther 2012;14:R142. http: //dx.doi.org/10.1186/ar3875.

68. Duffau P, Menn-Josephy H, Cuda CM, et al. Promotion of inflammatory arthritis by interferon regulatory factor 5 in a mouse model. Arthritis Rheumatol 2015;67:3146-57. http: //dx.doi.org/10.1002/art.39321.

69. Meng L, Zhu W, Jiang C, et al. Toll-like receptor 3 upregulation in macrophages participates in the initiation and maintenance of pristane-induced arthritis in rats. Arthritis Res Ther 2010;12:R103. http://dx.doi.org/10.1186/ar3034.

70. Zare F, Bokarewa M, Nenonen N, et al. Arthritogenic properties of double-stranded (viral) RNA. J Immunol 2004;172: 5656-63. http://dx.doi.org/10.4049/jimmunol.172.9.5656.

71. Yarilina A, DiCarlo E, Ivashkiv LB. Suppression of the effector phase of inflammatory arthritis by double-stranded RNA is mediated by type I IFNs. J Immunol 2007;178:220411. http://dx.doi.org/10.4049/jimmunol.178.4.2204.

72. Deng GM, Nilsson IM, Verdrengh M, et al. Intra-articularly localized bacterial DNA containing CpG motifs induces arthritis. Nat Med 1999;5:702-5. http://dx.doi.org/10.1038/ 9554.

73. Wu HJ, Sawaya H, Binstadt B, et al. Inflammatory arthritis can be reined in by CpG-induced DC-NK cell cross talk. J Exp Med 2007;204:1911-22. http://dx.doi.org/10.1084/ jem.20070285.

74. Choi Y, Arron JR, Townsend MJ. Promising bone-related therapeutic targets for rheumatoid arthritis. Nat Rev Rheumatol 2009;5:543-8. http://dx.doi.org/10.1038/nrrheum. 2009.175 .

75. Ikeda K, Takeshita S. Factors and mechanisms involved in 
the coupling from bone resorption to formation: how osteoclasts talk to osteoblasts. J Bone Metab 2014;21:163-7. http://dx.doi.org/10.11005/jbm.2014.21.3.163.

76. Marriott I. Osteoblast responses to bacterial pathogens: a previously unappreciated role for bone-forming cells in host defense and disease progression. Immunol Res 2004; 30:291-308. http://dx.doi.org/10.1385/ir:30:3:291.

77. Kassem A, Lindholm C, Lerner UH. Toll-Like receptor 2 stimulation of osteoblasts mediates staphylococcus aureus induced bone resorption and osteoclastogenesis through enhanced RANKL. PLoS One 2016;11:e0156708. http://dx.doi. org/10.1371/journal.pone.0156708.

78. Kassem A, Henning $P$, Lundberg $P$, et al. Porphyromonas gingivalis stimulates bone resorption by enhancing RANKL (receptor activator of NF-KB ligand) through activation of toll-like receptor 2 in osteoblasts. J Biol Chem 2015;290: 20147-58. http://dx.doi.org/10.1074/jbc.M115.655787.

79. Nakamura H, Fukusaki Y, Yoshimura A, et al. Lack of Toll-like receptor 4 decreases lipopolysaccharide-induced bone resorption in $\mathrm{C} 3 \mathrm{H} / \mathrm{HeJ}$ mice in vivo. Oral Microbiol Immunol 2008;23:190-5. http://dx.doi.org/10.1111/j.1399-302X. 2007.00410.x.
80. Kassem A, Henning P, Kindlund B, et al. TLR5, a novel mediator of innate immunity-induced osteoclastogenesis and bone loss. FASEB J 2015;29:4449-60. http://dx.doi.org/10. 1096/fj.15-272559.

81. Zou W, Amcheslavsky A, Bar-Shavit Z. CpG oligodeoxynucleotides modulate the osteoclastogenic activity of osteoblasts via Toll-like receptor 9. J Biol Chem 2003;278:1673240. http://dx.doi.org/10.1074/jbc.M212473200.

82. Ishihara $Y$, Nishihara T, Maki E, et al. Role of interleukin-1 and prostaglandin in in vitro bone resorption induced by Actinobacillus actinomycetemcomitans lipopolysaccharide. J Periodontal Res 1991;26:155-60. http://dx.doi.org/ 10.1111/j.1600-0765.1991.tb01639.x.

83. Graves DT, Alshabab A, Albiero ML, et al. Osteocytes play an important role in experimental periodontitis in healthy and diabetic mice through expression of RANKL. J Clin Periodontol 2018;45:285-92. http://dx.doi.org/10.1111/ jcpe. 12851

84. Anwar MA, Shah M, Kim J, et al. Recent clinical trends in Toll-like receptor targeting therapeutics. Med Res Rev 2019; 39:1053-90. http://dx.doi.org/10.1002/med.21553. 
